\title{
Persepsi Peserta PPG dalam Jabatan terhadap Pelaksanaan Program PPG Hybrid Learning Bidang Studi Matematika Universitas Negeri Jakarta Tahun 2019
}

\author{
Tri Murdiyanto \\ Program Studi Pendidikan Matematika FMIPA UNJ \\ Email: tmurdiyanto@unj.ac.id
}

\begin{abstract}
Abstrak
Pendidikan dan Latihan Profesi Guru (PLPG) mulaitahun 2018 sudah tidak dilaksanakan dengan alasan kurang adanya relevansi terhadap peningkatan profesionalitas guru. Pendidikan Profesi Guru (PPG) dirancang untuk menggantikan PLPG yang mulai dilaksanakan tahun 2016 yaitu PPG SM3T (Sarjana Mendidik di Daerah Terdepan, Terluar, dan Tertinggal) dimana pesertanya adalah para guru yang sudah melaksanakan tugas mengabdi di daerah 3T. Tahun 2018 dilaksanakan PPG Prajabatan bersubsidi dan tahun 2019 mulai dilaksanakan PPG da lam Jabatan. PPG SM3T dan Prajabatan bersubsidi dilaksa nakan secara tatap muka tetapi PPG dalam jabatan dilaksanakan menggunakan sistem Hybrid learning yang perupakan gabungan dari system daring dan sistem tatap muka dengan pertimbangan bahwa pesertanya adalah guru yang juga mempunyai tugas di sekolah sehingga tidak dapat terlalu lama meninggalkan tugas. Masalah yang muncul adalah apakah sistem PPG ini cocok untuk kondisi di Indonesia yang merupakan negara kepulauan dimana fasilita s pembelajarannya belum bisa mera ta dan a pakah para guru siap untuk belajar secara daring. Tujuan penelitian ini adalah untuk mendapatkan masukan dari peserta PPG dalam jabatan terhadap pelaksanaan PPG Hybrid Learning bidang studi matematika Universitas Negeri Jakarta tahun 2019. Metode penelitian yang digunakan adalah metode deskriptif, fokus penelitian pada persepsi peserta PPG terhadap pelaksanaan program PPG dala m jabatan Hybrid Learning. Persepsi peserta PPG yang diukur terdiri dari dua bagian yaitu 1) penerimaan atau penyerapan dan 2) evaluasi terhadap proses yang dijalani selama program dilaksanakan. Subyek penelitian ini adalah peserta PPG dalam jabatan bidang studi matematika FMIPA UNJ tahun 2019 tahap 1 sampai tahap 4 tahun 2019. Teknik pengumpulan data dengan menyebarkan angket kepada responden. Angket yang digunakan berupa gabungan angket tertutup dan terbuka yaitu tertutup dalam bentuk pernyataan yang pilihan ja wabannya sudah disediakan sedangkan terbuka untuk mendapatkan masukan mengembangkan proses pelaksanaan program PPG bidang studi matematika FMIPA UNJ. Hasil penelitian menunjukkan penerimaan atau penyerapan pada saat daring: kemudahan memperoleh sinyal internet, kemudahan menja lankan a plika si, memahami ca paian pembelajaran PPG, ketersedia an sumber belajar, kemampuan menyelesaikan tugas dan evalua si persentase yang menyatakan setuju dan sangat setuju lebih dari $80 \%$ namun yang tertarik/tertantang dengan pembelajaran daring hanya $40 \%$ dan yang merasakan beban sangat berat dalam pelaksanaan pembelajaran daring sebesar $75 \%$. Evaluasi proses yang menyangkut kesesuaian materi dan capaian pembelejaran, kesesuaian tugas dan evalua si dengan materi, kemampuan dan kinerja instruktur, pelayanan administrasi, fasilitas y ang memadahi, kemudahan pelaksanaan PPL dan kecukupan durasi waktu PPL persentase setuju dan sangat setuju diatas $75 \%$. Tetapi untuk kecukupan durasi waktu daring dan porsi materi hanya $55 \%$ yang setuju dan sangat setuju .
\end{abstract}

Kata kunci: persepsi, peserta PPG daljab, program PPG hybrid learning.

\section{PENDAHULUAN}

Universitas Negeri Jakarta adalah salah satu LPTK yang ditunjuk untuk melaksanakan sertifikasi guru melalui program Pendidikan Profesi Guru (PPG). Pelaksanaan program PPG dibedakan dalam 
dua kelompok yaitu PPG prajabatan dan PPG dalam jabatan, Berdasarkan pedoman penyelenggaraan program PPG tahun 2018 yang dimaksud PPG Prajabatan adalah PPG yang diperuntukkan bagi calon guru yang telah memenuhi persyaratan kualifikasi akademik S-1/D-IV dan akan melamar menjadi guru. Sedangkan PPG dalam jabatan adalah PPG yang diperuntukkan bagi guru dalam jabatan. Guru dalam Jabatan adalah guru pegawai negeri sipil dan guru bukan pegawai negeri sipil yang sudah mengajar pada satuan pendidikan baik yang diselenggarakan pemerintah pusat, pemerintah daerah, maupun masyarakat penyelenggara pendidikan yang sudah mempunyai perjanjian kerja atau kesepakatan kerja bersama.

PPG yang sudah dilaksanakan di Universitas Negeri Jakarta meliputi PPG prajabatan yaitu program dari SM3T dan program bersubsidi yang keduanya dilaksanakan secara face to face seperti program sarjana dan PPG dalam jabatan yang dikembangkan dengan mempertimbangkan bahwa guru yang mengikuti PPG diusahakan tidak terlalu lama meninggalkan sekolah berkaitan de ngan tugas mengajarnya yaitu melalui Program PPG Hybrid Learning. Kegiatan PPG Hybrid Learning dibagi dalam tiga tahap yaitu: 1) Tahap daring, 2) Tahap workshop, dan 3) Tahap Praktek Pengalaman Lapangan (PPL). Struktur kurikulum Program PPG Daljab dapat ditabulasikan sebagai Tabel berikut:

TABEL 1. Struktur Kurikulum Program PPG Daljab

\begin{tabular}{|l|l|c|c|c|c|}
\hline Kode & Mata Kegiatan PPG & sks & \multicolumn{3}{|c|}{ Kategori } \\
\cline { 4 - 7 } & & & T & P & L \\
\hline DAR1 & Pendalaman materi Pendidikan dan Profesi Pendidik & 4 & 4 & & \\
\hline DAR2 & $\begin{array}{l}\text { Pendalaman materi bidang studi dengan menerapkan prinsip } \\
\text { TPACK }\end{array}$ & 6 & 6 & & \\
\hline LOK1 & $\begin{array}{l}\text { Reviu dan diskusi hasil pendalaman materi melalui pembelajaran } \\
\text { daring }\end{array}$ & 1 & & 1 & \\
\hline LOK2 & Pengembangan Perangkat Pembelajaran dan Peer-Teaching & 6 & & 6 & \\
\hline LOK3 & Penyusunan Perencanaan Penelitian Tindakan Kelas (PTK) & 1 & & 1 & \\
\hline PPL & Praktik Pengalaman Lapangan & 6 & & & 6 \\
\hline Sub Jumlah & 24 & 10 & 8 & 6 \\
\hline Total & & & 24 & \\
\hline
\end{tabular}

Setelah selesai ketiga tahap diatas peserta PPG Hybrid Learning juga harus mengikuti tahap Uji Pengetahuan (UP) dan Uji Kinerja (UKIN). Sertifikat pendidik akan diterbitkan jika peserta lulus program PPG Hybrid Learning dan juga telah lulus UP dan UKIN.

PPG Hybrid Learning mulai dilaksanakan pada tahun 2018 sehingga tahun 2019 merupakan tahun ke dua pelaksanaan PPG Hybrid Learning. Tahun pertama pelaksanaan PPG Hybrid Learning tentu saja masih banyak masalah antara lain: (1) kuota peserta PPG dalam jabatan yang terlalu banyak sedangkan penyelenggara program PPG masih terbatas, (2) tidak semua daerah di Indonesia mempunyai akses internet yang mencukupi untuk melaksanakan program daring, (3) aplikasi baru yang digunakan untuk melaksanakan program daring belum dikuasai oleh peserta dan instruktur, (4) konten materi yang dibuat dalam waktu singkat sehingga masih ada yang kurang lengkap, (5) waktu pelaksanaan program daring yang singkat sedangkan modul yang harus dipelajari banyak sehingga membuat peserta PPG mengalami banyak kesulitan.

Tahun kedua sudah dilakukan revisi terhadap kelengkapan materi daring dan revisi instrument evaluasi yang ada dalam system, peningkatan kesiapan penyelenggara, kesiapan sarana dan prasarana, kesiapan instruktur daring, dan kesiapan peserta PPG untukmengikuti pembelajaran daring. Pada akhir tahun kedua ini perlu dilakukan evaluasi pelaksanaan program PPG Hybrid Learning perlu dilaksanakan dengan menampung masukan dari berbagai fihak antara lain penyelenggara, peserta, instruktur dan lain-lain untuk keperluan perbaikan system. Untuk keperluan tersebut akan dilakukan penelitian tentang bagaimana persepsi peserta PPG dalam jabatan terhadap pelaksanaan program PPG Hybrid Learning bidang studi matematika Universitas Negeri Jakarta tahun 2019. 
Rakhmat (2004:49) mendefinisikan persepsi ialah proses pemberian makna pada sensasi sehingga manusia memperoleh pengetahuan baru. Robbins (2008:97) mendeskripsikan bahwa persepsi merupakan kesan yang diperoleh oleh individu melalui panca indera kemudian dianalisis (diorganisisasi), diintepretasi dan kemudian dievaluasi, sehingga individu tersebut memperoleh makna, jadi seseorang yang pemperoleh persepsi terhadap sesuatu melalui proses analisis dan evaluasi. Indikator-indikator persepsi ada dua macam, yaitu: 1) Penerimaan atau penyerapan yaitu terjadinya persepsi dalam tahap fisiologis berfungsinya indera untuk menangkap rangsang dari luar, 2) Evaluasi yaitu mengevaluasi rangsang-rangsang dari luar yang telah ditangkap indera. Berdasarkan pendapat diatas, penelitian ini mendiskripsikan bahwa persepsi peserta PPG adalah sesuatu yang menyangkut hubungan para peserta PPG dan penyelenggara program PPG secaraintelektual beserta lingkungannya, bagaimana peserta PPG mengerti dan dapat menginterpretasi stimulus yang ada di lingkungannya dengan kritis dan pikiran jernih serta bertanggungjawab, kemudian diproses sehingga timbullah makna. Indikator yang akan digunakan dalam mengukur persepsi peserta PPG terdiri dari dua bagian yaitu 1) berkaitan dengan penerimaan atau penyerapan dan 2) berkaitan dengan evaluasi terhadap proses yang dijalani selama program dilaksanakan.

\section{TUJUAN}

Tujuan penelitian ini adalah untuk mendapatkan masukan dari pesertaPPG dalam jabatan terhadap pelaksanaan PPG Hybrid Learning bidang studi matematika Universitas Negeri Jakarta tahun 2019 yang berkaitan dengan proses pembelajaran daring, workshop dan program pengalaman lapangan.

\section{METODOLOGI}

Metode Penelitian yang digunakan dalam penelitian ini adalah penelitian deskriptif. Penelitian desktiptif adalah penelitian yang dilakukan untuk mengetahui nilai variabel mandiri, baik satu variabel atau lebih tanpa membuat perbandingan atau menghubungkan dengan variabel yang lain (Sugiyono, 2012). Penelitian ini menggambarkan data kuantitatif yang diperoleh menyangkut keadaan subjek atau fenomena dari sebuah pupulasinya. Teknik yang digunakan dalam penelitian ini adalah survai. Survai adalah pengumpulan informasi tentang sekelompok manusia, suatu hubungan langsung dengan objek yang dipelajari seperti individu, masyarakat, diadakan melalui suatu cara yang sistematis seperti pengisian daftar pertanyaan, angket, dan wawancara (Suparmoko, 1991:20).

Teknik pengambilan sampel yang digunakan dalam penelitian ini adalah sampling 'bertujuan' (purposive sampling). Sampling bertujuan adalah pengambilan sampel dengan pertimbanganpertimbangan tertentu (Arikunto, 2005:128). Populasi target pada penelitian adalah seluruh peserta PPG Hybrid Learning dalam jabatan bidang studi matematika FMIPA UNJ tahun 2019 yang terdiri dari 4 tahap yang dimulai dari bulan pebruari 2019 sampai bulan Nopember 2019. Sampel pada penelitian ini adalah seluruh peserta PPG Hybrid Learning dalam jabatan bidang studi matematika FMIPA UNJ tahun 2019 tahap 1 sampai tahap 4 yang berjumlah 112 orang. Pertimbanganpertimbangan yang digunakan dalam teknik pengambilan sampel pada penelitian ini yaitu sampel yang diambil adalah peserta program PPG Hybrid Learning dalam jabatan tahun 2019 yang pelaksanaannya dimulai pada bulan februari 2019 sampai bulan Oktober 2019 yang sesuai dengan waktu penelitian yang tersedia. Akan tetapi berkaitan dengan adanya peserta PPG yang mengundurkan diri karena berbenturan dengan kegiatan sebagai ASN baru (capeg) yang diterima tahun 2019 dan juga peserta PPG yang belum lulus UP sehingga tidak bersedia sebagai responden maka penelitian ini hanya bisa mengumpulkan responden sebayak 68 orang. Untuk mendapatkan data yang diperlukan dalam penelitian ini disusun instrumen dalam bentuk angket (kuesioner) yang berupa kombinasi angket tertutup dan terbuka. Alasan digunakan gabungan angket tertutup dan terbuka adalah agar dapat mendapatkan informasi dan masukan yang lebih luas dari responden. Angket disusun dalam bentuk pertanyaan-pertanyaan berdasarkan indikator penelitian. Indikator-indikator persepsi ada dua yaitu: 1) berkaitan dengan penerimaan atau penyerapan dan 2) berkaitan dengan evaluasi terhadap proses yang dijalani selama program dilaksanakan. Data dijaring/dikumpulkan melalui instrumen yang berbentuk 
kuisioner/angket yang harus diisi oleh semua peserta PPG Hybrid Learning dalam jabatan bidang studi matematika tahun 2019.

Teknik analisis data yang digunakan dalam penelitian ini adalah deskriptif kuantitatif dengan persentase. Setiap jawaban dijumlahkan lalu dibagi dengan banyaknya sampel (responden) dan dikalikan $100 \%$. Adapun rumus untuk menemukan hasilnya adalah sebagai berikut (Sudjiono, 2010:43): $\mathrm{P}=\mathrm{F} / \mathrm{N} \times 100 \%$, Keterangan: $\mathrm{P}=$ Nilai persentase, $\mathrm{F}=$ Frekuensi jawaban responden, $\mathrm{N}=$ Banyaknya Responden. Untuk mendapatkan gambaran yang jelas dan sistematis tentang obyek yang diteliti, data dari angket tertutup yang sudah terkumpul disajikan dalam bentuk eksplorasi data, yaitu berupa tabel, diagram, yang dilanjutkan dengan analisis statistik secara inferensial agar dapat lebih mudah untuk diinterpretasikan. Sedangkan data dari angket terbuka dikasifikasikan dan ambil inti dari masukan yang dapat digunakan sebagai masukan dalam perbaikan proses pelaksanaan PPG Hybrid Learning dalam jabatan bidang studi matematika yang akan datang.

Untuk mendapatkan data yang diperlukan dalam penelitian ini disusun instrumen dalam bentuk angket (kuesioner) yang berupa kombinasi angket tertutup dan terbuka. Alasan digunakan gabungan angket tertutup dan terbuka adalah agar dapat mendapatkan informasi dan masukan yang lebih luas dari responden. Indikator persepsi peserta PPG dalam jabatan terhadap pelaksanaan program PPG hybrid learning ada dua yaitu: (1) Penerimaan atau Penyerapan peserta PPG terhadap pelaksanaan PPG hybrid learning, (2) Evaluasi terhadap proses yang dijalani selama pelaksanaan PPG hybrid learning. Kedua indikator tersebut dilihat setelah melaksanakan program PPG hybrid learning yang terdiri dari 3 tahapan: (a) Pendalaman Materi dalam bentuk daring (dalam jaringan): materi diakses dari satu sumber belajar, dalamberbagai bentuk (teks, audio, video), diaksesmelalui Internet. (b) Workshop dan peer teaching: pelaksanaannya dilakukan di LPTK melalui tatap muka secara langsung. (c) PPL di sekolah mitra: pada tahap ini guru melakukan praktek pembelajaran secara langsung di kelas sekolah mitra.

\section{HASIL DAN PEMBAHASAN}

Prodi Pendidikan Matematika FMIPA UNJ pada tahun 2019 mendapatkan kuota melaksanakan PPG dalam jabatan sebanyak 6 rombel dengan durasi waktu yang dilaksanakan dalam 5 tahap yang dimulai bulan pebruari 2019. Tahap 1 satu rombel, tahap 2 satu rombel, tahap 3 satu rombel, tahap 4 satu rombel, dan tahap 5 dua rombel, setiap tahap durasi waktunya saling beririsan yaitu tahap 1 selesai kegiatan daring beralih ke kegiatan workshoptahap 2 harus mulai kegiatan daring dan seterusnya susul menyusul. Pelaksanaan tahap PPG yang demikian jelas sangat menyita waktu para dosen Pendidikan Matematika sehingga dengan berat hati untuk tahap 5 yang dua rombel terpaksa dikembalikan agar dipindahkan ke perguruan tinggi lain karena keterbatasan prodi Pendidikan Matematika berkaitan dengan penyediaan instruktur PPG. Proses pelaksanaan kegiatan dalam jabatan tahap 1 sampai 4 saat ini sudah selesai mulai dari kegiatan daring, workshop/peerteaching, PPL, UKIN dan UP.

Quesioner penelitian ini di edarkan ke peserta PPG memalui google form yang diisi secara daring oleh peserta PPG sebagai responden sebanyak 68 orang dengan hasil sbb:

\section{Sebaran Responden}

Jumlah responden dalam penelitian ini adalah 68 orang dengan rincian seperti tabel di bawah ini:

TABEL 2. Sebaran Responden Penelitian

\begin{tabular}{|c|c|c|c|}
\hline No & Tahap PPG & Responden Laki-laki & Responden Perempuan \\
\hline 1 & Tahap 1 & 5 & 15 \\
\hline 2 & Tahap 2 & 9 & 8 \\
\hline 3 & Tahap 3 & 5 & 7 \\
\hline 4 & Tahap 4 & 3 & 17 \\
\hline \multicolumn{2}{|l|}{ Jumah } & 22 & 47 \\
\hline
\end{tabular}




\section{Hasil pada indikator Penerimaan atau Penyerapan}

Indikator Penerimaan atau Penyerapan peserta PPG terhadap pelaksanaan PPG hybrid learning terdiri dari 20 pernyataan dengan hasil pada tiap-tiap pernyataan sebagai berikut:

TABEL 3. Persentase Respon Indikator Penerimaan atau Penyerapan

\begin{tabular}{|c|c|c|c|c|c|}
\hline No. & Pernyataan & $\begin{array}{l}\text { ST } \\
(\%)\end{array}$ & $\begin{array}{c}\mathbf{S} \\
(\%)\end{array}$ & $\begin{array}{l}\text { TS } \\
(\%) \\
\end{array}$ & $\begin{array}{l}\text { STS } \\
(\%)\end{array}$ \\
\hline 1 & $\begin{array}{l}\text { Saya tidak mengalami kesulitan dalam memperoleh sinyal } \\
\text { internet di daerah tempat saya mengajar }\end{array}$ & 32.4 & 54.4 & 11.8 & 1.5 \\
\hline 2 & $\begin{array}{l}\text { Saya dengan mudah dapat menjalankan aplikasi pembelajaran } \\
\text { daring PPG hybrid learning dengan bantuan panduan. }\end{array}$ & 25 & 73.5 & 1.5 & 0 \\
\hline 3 & $\begin{array}{l}\text { Saya mengetahui capaian pembelajaran PPG hybrid learning } \\
\text { untuk bidang studi matematika. }\end{array}$ & 17.1 & 72.1 & 10.3 & 0 \\
\hline 4 & $\begin{array}{l}\text { Saya lebih tertarik dan tertantang dalam belajar menggunakan } \\
\text { pembelajaan daring PPG dari pada pembelajaran tatap muka. }\end{array}$ & 4.4 & 50 & 44.1 & 1.5 \\
\hline 5 & $\begin{array}{l}\text { Pembelajaran daring PPG menyediakan sumber belajar yang } \\
\text { lebih bervariasi (teks video, audio) yang mempermudah saya } \\
\text { dalam belajar. }\end{array}$ & 14.7 & 76.5 & 8.8 & 0 \\
\hline 6 & $\begin{array}{l}\text { Saya dapat memanfaatkan fasilitas forum diskusi secara efektif } \\
\text { dan efisien untuk mendiskusikan materi pembelajaran daring } \\
\text { PPG }\end{array}$ & 10.3 & 61.8 & 27.9 & 0 \\
\hline 7 & $\begin{array}{l}\text { Saya mempunyai waktu yang cukup leluasa dalam mempelajari } \\
\text { materi dalam pembelajaran daring PPG }\end{array}$ & 4.4 & 33.8 & 57.4 & 4.4 \\
\hline 8 & $\begin{array}{l}\text { Tugas-tugas yang diberikan dalam pembelajaran daring PPG } \\
\text { dapat saya selesaikan sesuai waktu yang ditentukan. }\end{array}$ & 14.7 & 75 & 10.3 & 0 \\
\hline 9 & $\begin{array}{l}\text { Saya merasa yakin dapat menyelesaikan evaluasi yang diberikan } \\
\text { dalam pembelajaran daring PPG }\end{array}$ & 10.3 & 77.9 & 11.8 & 0 \\
\hline 10 & $\begin{array}{l}\text { Pada saat pelaksanaan pembelajaran daring PPG tugas mengajar } \\
\text { disekolah saya masih tetap dapat saya laksanakan sesuai jadwal. }\end{array}$ & 10.3 & 66.2 & 23.5 & 0 \\
\hline 11 & $\begin{array}{l}\text { Saya merasakan beban yang sangat berat pada saat melaksanakan } \\
\text { pembelajaran daring PPG. }\end{array}$ & 10.3 & 67.6 & 22.1 & 0 \\
\hline 12 & $\begin{array}{l}\text { Saya lebih merasasantai dan senang saat melaksanakan workshop } \\
\text { tatap muka di kampus daripada PPG daring }\end{array}$ & 14.7 & 69.1 & 16.2 & 0 \\
\hline 13 & $\begin{array}{l}\text { Saya lebih puas melaksanakan diskusi pada saat workshop karena } \\
\text { proses diskusi dapat berkembang lebih luas. }\end{array}$ & 35.3 & 60.3 & 4.4 & 0 \\
\hline 14 & $\begin{array}{l}\text { Saya mempunyai waktu yang cukup leluasa dalam penyusun } \\
\text { perangkat pembelajaran pada saat workshop }\end{array}$ & 23.5 & 66.2 & 10.3 & 0 \\
\hline 15 & $\begin{array}{l}\text { Saya dapat menyelesaikan semua tugas yang menjadi tanggung } \\
\text { jawab saya dalam pelaksanaan workshop sesuai waktu yang } \\
\text { disediakan. }\end{array}$ & 25 & 75 & 0 & 0 \\
\hline 16 & $\begin{array}{l}\text { Saya merasa yakin dapat mengerjakan evaluasi yang diberikan } \\
\text { pada akhir workshop. }\end{array}$ & 22.1 & 75 & 2.9 & 0 \\
\hline 17 & $\begin{array}{l}\text { Saya merasakan beban yang sangat berat pada saat melaksanakan } \\
\text { workshop dan peerteaching }\end{array}$ & 0 & 26.5 & 69.1 & 4.4 \\
\hline 18 & $\begin{array}{l}\text { Peerteaching sangat saya perlukan sebelum penerapan } \\
\text { pembelajaran di kelas nyata. }\end{array}$ & 29.4 & 69.1 & 1.5 & 0 \\
\hline 19 & $\begin{array}{l}\text { Di Sekolah mitra PPL semua guru menerima saya dengan baik } \\
\text { dan guru pamong membimbing secara maksimal. }\end{array}$ & 45.6 & 51.5 & 2.9 & 0 \\
\hline 20 & $\begin{array}{l}\text { Saya mempunyai waktu yang cukup untuk latihan mengajar } \\
\text { sebelum pelaksanaan ujian PPL dan UKIN. }\end{array}$ & 27.9 & 61.8 & 10.3 & 0 \\
\hline
\end{tabular}


Dari tabel diatas dapat di interpretasikan bahwa:

1) Lebih dari $80 \%$ peserta PPG tidak mengalami kesulitan dalam memperoleh sinyal internet

2) Lebih dari $90 \%$ peserta PPG dengan mudah dapat menjalankan aplikasi pembelajaran daring

3) Lebih dari $80 \%$ peserta PPG mengetahui capaian pembelajaran PPG.

4) Lebih dari $50 \%$ peserta PPG lebih tertarik dan tertantang dalam belajar menggunakan pembelajaan daring PPG dari pada pembelajaran tatap muka

5) Lebih dari $90 \%$ peserta PPG menyatakan pembelajaran daring PPG menyediakan sumber belajar yang lebih bervariasi (teks video, audio) yang mempermudah dalam belajar.

6) Lebih dari $70 \%$ peserta PPG dapat memanfaatkan fasilitasforum diskusi secara efektif danefisien untuk mendiskusikan materi pembelajaran daring PPG

7) Kurang dari $40 \%$ peserta PPG yang mempunyai waktu yang cukup leluasa dalam mempelajari materi dalam pembelajaran daring PPG

8) Lebih dari $80 \%$ peserta PPG dapat menyelesaikan tugas-tugas sesuai waktu yang ditentukan

9) Lebih dari $80 \%$ peserta PPG dapat menyelesaikan evaluasi yang diberikan dalam pembelajaran daring PPG.

10) Lebih dari $75 \%$ peserta PPG dapat melaksanakan tugas mengajar di sekolah sesuai jadwal

11) Lebih dari $75 \%$ peserta PPG merasakan beban yang sangat berat pada saat melaksanakan pembelajaran daring PPG.

12) Lebih dari $80 \%$ peserta PPG merasakan santai dan senang saat melaksanakan workshop tatap muka di kampus daripada PPG daring.

13) Lebih dari $95 \%$ peserta PPG lebih puas melaksanakan diskusi pada saat workshop karena proses diskusi dapat berkembang lebih luas.

14) Lebih dari $85 \%$ peserta PPG mempunyai waktu yang cukup leluasa dalam penyusun perangkat pembelajaran pada saat workshop.

15) $100 \%$ peserta PPG dapat menyelesaikan semua tugas dalam pelaksanaan workshop sesuai waktu yang disediakan.

16) Lebih dari $95 \%$ peserta PPG yakin dapat mengerjakan evaluasi yang diberikan pada akhir workshop

17) Kurang dari $30 \%$ peserta PPG yang merasa beban sangat berat saat melaksanakan workshop dan peerteaching

18) Lebih dari $90 \%$ peserta PPG memerlukan peerteaching sebelum menerapkan di kelas nyata

19) Lebih dari $95 \%$ peserta PPG dapat diterima dengan baik dan dibimbing guru pamong secara maksimal

20) Lebih dari $85 \%$ peserta PPG mempunyai waktu yang cukup untuk latihan mengajar sebelum pelaksanaan ujian PPL dan UKIN

\section{Hasil pada Indikator Evaluasi Proses}

Indikator evaluasi terhadap proses yang dijalani selama pelaksanaan PPG hybrid learning terdiri dari 15 pernyataan dengan hasil pada tiap-tiap pernyataan sebagai berikut:

TABEL 4. Persentase Respon Indikator Evaluasi Proses

\begin{tabular}{|c|l|c|c|c|c|}
\hline No. & \multicolumn{1}{|c|}{ Pernyataan } & $\begin{array}{c}\text { ST } \\
(\boldsymbol{\%})\end{array}$ & $\begin{array}{c}\text { S } \\
(\mathbf{\%})\end{array}$ & $\begin{array}{c}\text { TS } \\
(\boldsymbol{\%})\end{array}$ & $\begin{array}{c}\text { STS } \\
(\boldsymbol{\%})\end{array}$ \\
\hline 1 & $\begin{array}{l}\text { Materi daring PPG sesuai dengan capaian pembelajaran PPG } \\
\text { baik pedagogik maupun professional }\end{array}$ & 13.2 & 76.5 & 10.3 & 0 \\
\hline 2 & $\begin{array}{l}\text { Tugas dan evaluasi dalam pembelajaran daring PPG sesuai } \\
\text { dengan materi yang diberikan. }\end{array}$ & 14.7 & 77.9 & 7.4 & 0 \\
\hline 3 & $\begin{array}{l}\text { Durasi waktu daring PPG sesuai dengan porsi materi yang harus } \\
\text { dipelajari }\end{array}$ & 7.4 & 51.5 & 38.2 & 2.9 \\
\hline 4 & $\begin{array}{l}\text { Sebagian besarinstruktur melaksanakan pembelajaran daring } \\
\text { sesuai waktu yang diberikan. }\end{array}$ & 10.3 & 79.4 & 8.8 & 1.5 \\
\hline
\end{tabular}




\begin{tabular}{|c|l|c|c|c|c|}
\hline No. & \multicolumn{1}{|c|}{ Pernyataan } & $\begin{array}{c}\text { ST } \\
(\%)\end{array}$ & $\begin{array}{c}\text { S } \\
(\%)\end{array}$ & $\begin{array}{c}\text { TS } \\
(\%)\end{array}$ & $\begin{array}{c}\text { STS } \\
(\%)\end{array}$ \\
\hline 5 & $\begin{array}{l}\text { Sebagian besar Instruktur memberikan masukan yang cukup } \\
\text { dalam forum diskusi maupun dalam tugas yang dikerjakan }\end{array}$ & 11.8 & 66.2 & 20.6 & 1.5 \\
\hline 6 & $\begin{array}{l}\text { Hasil akhir pembelajaran daring PPG segera dapat diakses oleh } \\
\text { peserta }\end{array}$ & 14.7 & 77.9 & 7.4 & 0 \\
\hline 7 & $\begin{array}{l}\text { Pelayanan administrasi pendaftaran ulang untuk workshop } \\
\text { memadahi. }\end{array}$ & 20.6 & 77.9 & 1.5 & 0 \\
\hline 8 & $\begin{array}{l}\text { Ruang yang digunakan untuk workshop memadahi (cahaya, } \\
\text { kesejukan ruang dan fasilitas pendukung) }\end{array}$ & 30.9 & 66.2 & 1.5 & 1.5 \\
\hline 9 & Sebagian besarinstruktur menguasai materi workshop & 26.5 & 61.8 & 10.3 & 1.5 \\
\hline 10 & Instruktur banyak memberi masukan dalam proses workshop & 25 & 69.1 & 4.4 & 1.5 \\
\hline 11 & $\begin{array}{l}\text { Peerteacing dilaksanakan dengan mengundang guru untuk } \\
\text { memberi masukan }\end{array}$ & 19.1 & 60.3 & 20.6 & 0 \\
\hline 12 & Sekolah mitra PPL sesuai dengan tingkat sekolah asal. & 40.3 & 53.7 & 4.5 & 1.5 \\
\hline 13 & $\begin{array}{l}\text { Waktu yang tersedia untuk PPL cukup untuk melaksanakan } \\
\text { latihan mengajar dan ujian }\end{array}$ & 32.4 & 58.8 & 8.8 & 0 \\
\hline 14 & $\begin{array}{l}\text { Koordinasi pelaksanaan ujian PPL dan UKIN memadahi } \\
\text { sehingga berjalan lancar. }\end{array}$ & 29.4 & 69.1 & 1.5 & 0 \\
\hline 15 & $\begin{array}{l}\text { Bagi peserta yang belum lulus UP/UKIN segera mendapat } \\
\text { kepastian untuk pelaksanaan ujian susulan. }\end{array}$ & 19.4 & 74.6 & 6 & 0 \\
\hline
\end{tabular}

Dari tabel diatas dapat di interpretasikan bahwa:

1) lebih dari $85 \%$ peserta PPG menyatakan materi daring PPG sesuai dengan capaian pembelajaran PPG baik pedagogik maupun professional

2) lebih dari $90 \%$ peserta PPG menyatakan tugas danevaluasi dalam pembelajaran darin g PPG sesuai dengan materi yang diberikan.

3) lebih dari 55\% peserta PPG menyatakan durasi waktu daring PPG sesuai dengan porsi materi yang harus dipelajari

4) lebih dari $85 \%$ peserta PPG menyatakan sebagian besar instruktur melaksanakan pembelajaran daring sesuai waktu yang diberikan.

5) lebih dari $75 \%$ peserta PPG menyatakan sebagian besar instruktur memberikan masukan yang cukup dalam forum diskusi maupun dalam tugas yang dikerjakan

6) lebih dari $90 \%$ peserta PPG menyatakan hasil akhir pembelajaran daring PPG segera da pat diakses oleh peserta

7) lebih dari $95 \%$ peserta PPG menyatakan pelayanan administrasi pendaftaran ulang untuk workshop memadahi

8) lebih dari $95 \%$ peserta PPG menyatakan ruang yang digunakan untuk workshop memadahi (cahaya, kesejukan ruang dan fasilitas pendukung)

9) lebih dari $85 \%$ peserta PPG menyatakan sebagian besar instruktur menguasai materi workshop

10) lebih dari $90 \%$ peserta PPG menyatakan instruktur banyak memberi masukan dalam proses workshop

11) lebih dari $75 \%$ peserta PPG menyatakan instruktur banyak memberi masukan dalam proses workshop

12) lebih dari $90 \%$ peserta PPG menyatakan sekolah mitra PPL sesuai dengan tingkat sekolah asal

13) lebih dari $90 \%$ peserta PPG menyatakan waktu yang tersedia untuk PPL cukup untuk melaksanakan latihan mengajar dan ujian

14) lebih dari 95\% peserta PPG menyatakan koordinasi pelaksanaan ujian PPL dan UKIN memadahi sehingga berjalan lancar

15) lebih dari $90 \%$ pesertaPPG menyatakan bagi peserta yang belumlulus UP/UKIN segera mendapat kepastian untuk pelaksanaan ujian susulan 


\section{Masukan Pernyataan Terbuka}

Pernyataan terbuka pada questioner digunakan untuk menjaring masukan dari peserta PPG untuk perbaikan pelaksanaan program PPG ke depan. Masukan yang diperoleh setelah dilakukan reduksi pernyataan yang sejenis diperoleh beberapa pernyataan sebagai berikut:

1) Untuk pembelajaran workshop ditambah dengan membahas soal soal yang keluar di ujian pengetahuan.

2) Perlu tambahan durasi waktu dalam pembelajaran daring.

3) Kelulusan PPG penilaiannya harusnya dari komponen daring, workshop, PPL, UKIN, dan UP, jadi tidak berdasarkan UP saja.

4) Penjadwalan daring agar tidak mengganggu aktivitas sekolah asal.

5) Untuk kelas Matematika lebih cocok tatap muka, daring kurang cocok dengan kelas matematika.

6) Sebaiknya untuk PPL di kembalikan ke sekolah asal.

7) Durasi waktu peer teaching diperpanjang $2 \times 45$ menit supaya maksimal ketika pendalaman soal.

8) Fasilitas meja yang dipakai agar aman untuk meletakkan laptop.

9) Segera memberikan informasi pelaksanaan Ujian Pengetahuan Ulang.

10) Profesionalitas dosen LPTK sangat diperlukan.

11) Untuk ujian UP mohon dikoreksi kembali soal dan pilihan jawaban yg diberikan, karena ada beberapa soal yang tidak ada jawabannya.

12) Mempercepat proses pencetakan sertifikat bagi yang sudah lulus.

13) Kegiatan workshop lebih lama, sering disimulasikan dalam peer teaching dengan kuantitas yang lebih banyak.

14) PPL sebaiknya dilakukan banyak latihan mengajar untuk proses menjadi guru professional.

15) Saran untuk pelaksanaan PPG daring tidak bersamaan dengan waktu sekolah efektif tapi diwaktu weekand mulai dari jumat malam sampai minggu malam.

16) Pengambilan sertifikat kelulusan sebaiknya langsung ke UNJ tidak melalui LPMP karena memakan waktu lama.

17) Disediakan waktu khusus bagi peserta untuk berlatih menyelesaikan soal-soal untuk persiapan UP dengan didampingi instruktur yang menguasai materi agar kelulusan UP bisa lebih maksimal.

\section{PENUTUP}

\section{Kesimpulan}

Persepsi Peserta PPG Dalam Jabatan Terhadap Pelaksanaan Program PPG Hybrid Learning Bidang Studi Matematika Universitas Negeri Jakarta Tahun 2019 yang berkaitan dengan indikator penerimaan atau penyerapan sebagian besar sudah sangat baik yaitu setuju dan sangat setuju diatas 80 $\%$ pada saat daring kemudahan memperoleh sinyal internet, kemudahan menjalankan aplikasi, memahami capaian pembelajaran PPG, ketersediaan sumber belajar, kemampuan menyelesaikan tugas dan evaluasi, namun yang setuju dapat memanfaatkan forum diskusi daring secara efektif hanya sekitar $70 \%$, yang tertarik/tertantang dengan pembelajaran daring hanya $40 \%$ dan $75 \%$ merasakan beban sangat berat dalam pembelajaran daring. Sedangkan pada saat workshop dan PPL hanya $30 \%$ yang merasakan beban sangat berat. Peserta PPG lebih senang dengan situasi workshop dan PPL daripada daring. Untuk indikatorevaluasi proses yang menyangkut kesesuaian materi dan capaian pembelejaran, kesesuaian tugas dan evaluasi dengan materi, kemampuan dan kinerja instruktur, pelayanan administrasi, fasilitas yang memadahi, kemudahan pelaksanaan PPL dan kecukupan durasi waktu PPL semua setuju dan sangat setuju diatas $75 \%$. Tetapi untuk kecukupan durasi waktu daring dan porsi materi hanya $55 \%$ yang setuju dan sangat setuju.

Saran untuk pelaksanaan PPG ke depan dari masukan peserta antara lain: (1) Pengaturan waktu pelaksanaan PPG dengan memperhitungkan kemampuan peserta PPG yang juga mempunyai tu gas di sekolah dan juga kemampuan perguruan tinggi untuk melaksanakan (tidak saling beririsan antara satu tahap dan tahap berikutnya), (2) Pengaturan ulang rumusan kelulusan PPG dari semua komponen 
dengan pembobotan yang seimbang, (3) Menambah waktu pemantapan Ujian Pengetahuan untuk latihan soal dan trayout UP.

\section{REFERENSI}

Arikunto, Suharsimi. 2005. Manajemen Penelitian.Jakarta: PT Rineka Cipta.

Permendiknas No. 8 Tahun 2009 tentang Pendidikan Profesi Guru.

Peraturan Pemerintah Republik Indonesia nomor 74 tahun 2008

Peraturan Pemerintah Republik Indonesia nomor 19 tahun 2017

Rakhmat, Jalaludin. 2004. Metode Penelitian Komunikasi. Bandung: Remaja Rosdakarya.

Robbins, Stephen P. 2008. Perilaku Organisasi Buku 1, Edisi 12. Diterjemahkan oleh Diana Angelica. Jakarta: Salemba Empat.

Singgih, Santoso. 2003. Statistik Deskriptif Konsep dan Aplikasi dengan Microsoft Excel dan SPSS. Yogyakarta: Andi Offiset.

Sudjiono, Anas. 2010. Pengantar Statistik Pendidikan, Jakarta: Rajawali Press.

Sugiyono. 2012. Metode Penelitian Pendidikan Pendekatan Kuanti-tatif, Kualitatif, dan R\&D. Bandung: Alfabeta.

Suparmoko. 1991. Metode Penelitian Praktis. Yogyakarta: BPFE

Tim Penyusun Kamus Pusat Pembinaan dan Pengembangan Bahasa, 1998, Kamus Besar Bahasa Indonesia. Jakarta: Balai Pustaka.

Undang-Undang Nomor 14/2005 tentang guru dan dosen 